\title{
Relating the Learned Knowledge and Acquired Skills to Real Life: Function Sample
}

\author{
Mustafa Albayrak ${ }^{1}$, Nurullah Yazıcı ${ }^{2} \&$ Mertkan Şimşek ${ }^{3}$ \\ ${ }^{1}$ Kazım Karabekir Education Faculty, Ataturk University, Erzurum, Turkey \\ ${ }^{2}$ Institute of Education Faculty, Ataturk University, Erzurum, Turkey \\ ${ }^{3}$ Education Faculty, Ağrı İbrahim Çeçen University, Ağrı, Turkey \\ Correspondence: Mertkan Şimşek, Education Faculty, Ağrı İbrahim Çeçen University, Ağrı, Turkey. E-mail: \\ mertkans@gmail.com
}

Received: June 24, 2017

Accepted: July 13, 2017

Online Published: August 16, 2017

doi:10.5539/hes.v7n3p148

URL: http://doi.org/10.5539/hes.v7n3p148

\begin{abstract}
Considering that Mathematics is a multidimensional problem-solving method that can be effective in all areas of cultural life, it is of great importance because of its contribution to other sciences such as physical and social sciences. It is known that the basic concepts of mathematics, which can also be expressed as a way of life, have helped to increase the usefulness of mathematics to practical and even social sciences such as physics, chemistry, biology, economics, engineering and military, as well as their own values. In addition, if abstract subjects and concepts in mathematics are used in other sciences, concrete results can be obtained, which facilitate the labor of humans. In this case, it is useful to illustrate the mathematics of everyday life in order to understand the importance of mathematics. The word "function", which is often used in everyday life as in mathematics, is one of the basic concepts in mathematics. Relating the learned knowledge and the acquired skills related to this concept to everyday life can affect the memory duration of learned knowledge and subsequent learning. Considering the importance of the subject, a case study has been conducted with (62) students. In the study, the definition of the function and two daily life examples related to the definition were presented to the candidates in black and white. The candidates were asked to make the definition of the types of functions presented to make sampling from daily life by making analogies. Content analysis was used in the analysis of the data. In the study, it was determined that the candidates could not go beyond the ordinary in writing samples. In addition, the success rates of candidates' ability to define and write daily life examples have been quite different.
\end{abstract}

Keywords: function, association, sampling, examples of everyday life

\section{Introduction}

The concept of function is known to be a concept that has been developed from past to present by those who are interested in mathematics by approaching from different angles and has a feature that separate classical mathematics from modern mathematics (Kleiner, 1989; Ponte, 1992; Eisenberg, 2002). Firstly, in 1673 Leibniz described this newly developed concept as a "function" by showing that it is a tangential curve function. Later on, by Euler, Dirichlet, Baire, Borel, and Lebesgue, this definition has been directed towards the notion that function is a kind of mapping beyond being considered as a curved or analytical expression (Markovits et al., 1986; Kleiner, 1989). In 1939, after Bourbaki (2004) stated that this mapping had to be done according to a basis, it took its place in today's textbooks with the definition of Drichlet-Bourbaki. According to this definition, on condition that with any two sets A and B different from empty set, a relation from A to B which maps each unit in set A to one and only one element in set B is called as "function" (Markovits et al., 1986).

Within mathematical concepts, the concept of function is one of the important and difficult concepts that students have difficulty in understanding and teachers have difficulty in describing, as well (Hitt, 1998). However, mathematical concepts are concepts related to each other, and each concept is a prior knowledge for the next concept. In this context, Altun (1998) stated that the deficiencies in the learning of function concepts may cause difficulties in learning many concepts such as logarithm, limit, derivative, integral and trigonometry.

It is known that the concept of function is related to many other mathematical concepts. Despite being in an important position in mathematics, it was found according to the results of several researches that students 
cannot learn the function concept sufficiently. Işık, Albayrak, and İpek (2005), in their study with pre-service teachers taking mathematics education at a university, have found that pre-service teachers have conceptual misconceptions about function-related concepts as well as lack of knowledge about the definition of the function concept. One of the studies conducted in this field is the research conducted by Winner and Dreyfus (1989). The aim of the study was to investigate the perceptions of students who were studying at universities about the function concept. As a result of the research, Vinner and Dreyfus (1989) found that the students did not understand the function definition sufficiently and they reported that the students expressed unrelated examples about the definition of function. Sajka (2003), on the other hand, stated that the use of the Dirichlet-Bourbaki definition in the teaching of the function concept caused difficulties for students to understand the function concept. It was stated that the reason behind this situation is that students cannot relate the function taught with the Dirichlet-Bourbaki definition to their daily lives. In addition to these, Türkeli Şandır (2006) concluded that pre-service teachers have difficulties in relating the concepts such as function, graphical representation of functions, linear function, one-to-one and surjective function and inverse function to daily life. In order to overcome these problems, he stated that while the concept of function is introduced to the students for the first time, daily life samples must be selected and associated with everyday life and in this way, the students will be able to better understand the functions and other concepts in the function. In the direction of this study, Bayazit and Aksoy (2013) have shown that associating these concepts with each other and daily life in the teaching of basic concepts such as one-to-one function, surjective function, linear function, unit function and constant function will help provide meaningful learning to students about these concepts. In addition to these studies, Ural (2006) stated that analogies can be used to teach functions, one-to-one functions, surjective functions and other concepts, starting from the relations between mother (definition set) and child (value set).

The analogy is defined as expressing an unknown situation by using a situation known from past life experiences (Küçükturan, 2003). It is possible to see analogies of different uses ranging from young children to scientists who make the most famous discoveries. On the one hand, it is the result of analogies that a child in the preschool era understands the lungs through two balloons, and Archimedes finds the buoyancy of water through bowl's floating in the water (Kanalmaz, 2010). When it is considered from the perspective of the Archimedes' example, the previously known object (bowl's floating on the water) is called analogy while the newly learned object (buoyancy of water) is called the target concept (Spellman \& Holyoak, 1996). According to Shulman (1986), teachers need to master the use of analogies in order to adjust their field knowledge to different levels of students, and this is an important part of pedagogical knowledge.

Another important situation in which teachers' daily life associations can provide a response is to provide an environment of argumentation to the students. With an argument-based learning approach, students have the opportunity to ask questions, test their arguments, create proposals parallel to the arguments being tested, and support decision-making processes with scientific knowledge (Burke, Greenbowe, \& Hand, 2006). At this point, the quality and quantity of the arguments created by the students are in parallel with the fact that the environment of argumentation is related to daily life (Torun \& Sahin, 2016; Duran, Doruk, \& Kaplan, 2017).

One of the problems in the field of mathematics education is how to provide meaningful and permanent learning to the students. In order to understand the mathematical concepts and the relations between these concepts in detail and to develop these relations, it is a requirement for meaningful and persistent learning that students use different notation methods, make comparisons, and relate these concepts to each other (NCTM, 2000). Meaningful and permanent learning will be provided by having the concepts that students learn during the learning phase be confronted with the question "Why do they learn?" and by associating the concepts that will be taught with daily life and by reinforcing them with examples (Enginar et al., 2002; Moon, 2008).

It is a known fact that teachers, students or any individual use mathematical concepts in a way, knowingly or unknowingly, in everyday life. When describing mathematics, Dönmez (2002) stated that he considered mathematics as "the abstracted form of life". In this sense, knowing mathematical concepts and mathematics at a certain level can be considered as a good understanding of life therefore in daily life, you can find an application area in which mathematics is. For this reason, the aim of the mathematics taught in schools is to train individuals who have the ability to solve problems that individuals may encounter in everyday life through mathematical applications (TTKB, 2016). It has been determined that concepts taught based on everyday life constitute a more willing learning environment, contributes positively to the motivation of the students, and helps the students to increase their success by providing more meaningful and permanent learning (Koştu, 2010; Koçak \& Önen, 2012). However, it has been determined that students who succeed in mathematics in school do not succeed in solving the problems they encounter in daily life (Umay \& Kaf, 2005) or, on the contrary, it has been found that people who successfully use mathematics in everyday life do not have a successful attitude to express 
mathematical thinking (Sternberg, 1999). The reason for this situation is that the school mathematics is taught independently or in a disconnected way from everyday life (Coştu et al., 2010). In this study, it is aimed to show the degree to which the pre-service teachers can relate the function concept and daily life in the teaching of the function concept. In the study, the definition of function and two daily life examples related to function concept are written, the types of functions are drawn in a schema, and the pre-service teachers are asked to write the definition of each type of function as well as write daily life examples for each type of function. In the study, it was aimed to determine the ability of the pre-service teachers to define the known and also written function concept by making analogies related to daily life and to write examples related to them.

In this direction, the sub-problems of the study are as follows:

1) Can the pre-service teachers define other functions (one-to-one, surjective, unit, constant) by making analogies of the definition of function that is written?

2) Do the pre-service teachers relate the knowledge and skills they have acquired by making analogies of the examples of the function concept presented in black and white to the daily life situations?

\section{Method}

Qualitative research design was used in this research. In the study, the skills and knowledge of the pre-service teachers about defining the functions whose names and figures are presented in black and white and their ability to make analogies of the function through daily life examples (two) and to write examples related to these functions from daily life. The case study allows an in-depth study of a particular situation and to describe the situation (Creswell, 2012). In this direction, 62 third-grade elementary mathematics education students studying at a State University are of the study. Availability sampling method was used and the participants were informed about the subject before the study and volunteerism was taken as basis. In the presentation of the data, the pre-service teachers were given the codes as $\mathrm{T} 1, \mathrm{~T} 2 \ldots$ and the answers given by the pre-service teachers were presented in direct citations.

As a data collection tool, "Associations of Functions with Daily Life Form (AFWDLF)" was prepared by researchers. In the prepared form, after the formal definition of the function is written, schemas representing the types of functions (one-to-one function, injective function, constant function, surjective function and unit function) are drawn and it is asked to write the related daily life example by making the definition of the related function.

In the analysis of the data, content analysis was used. The data were analyzed for conformity for the definition of function, for each type of function and for all types together. Descriptive statistics were used to provide information about the distribution of participants' answers. Findings were supported with direct quotations of the answers that participants wrote in AFWDLF forms. The results obtained in this direction are categorized according to function definition and function types. In addition, the cases encountered during content analysis are also explained in the relevant category.

\section{Findings}

In this section, the findings obtained from the study are written in the categories as being able to make definitions of each function (one-to-one, injective, constant, surjective, unit) and associating it with daily life.

\subsection{Defining Function}

\subsubsection{Defining One-to-One Function}

In this section, the pre-service teachers were asked to make a definition of one-to-one function.

Table 1. Defining one-to-one function

\begin{tabular}{lcc}
\hline & $\mathrm{f}$ & $\%$ \\
\hline Correct & 41 & 66.2 \\
Wrong & 12 & 19.3 \\
Null & 9 & 14.5 \\
\hline
\end{tabular}

According to Table 1 , it can be said that the vast majority of pre-service teachers have successfully written the definition of one-to-one function. Some of the written correct definitions are as follow: 
$T 43=$ Given $A$ and $B$ set different from empty set, the relation which maps each element of $A$ to one and only element of $B$ is called one-to-one function from $A$ to $B$.

$T 5=A, B \neq \varnothing$, that each element in A set maps only one element in $B$ set is called one-to-one function.

Some of the written wrong definitions are as follow:

T53=Take $A$ and $B$ as two sets, each value in $A$ maps one value in $B$.

$T 10=I t$ is the function which maps each element in $A$ to the way that there is no element is empty in $B$.

When we look at the wrong definitions, we think that when defining, T53 and T10 ignored that "the image of each element in the definition set is different from the images of other elements" (MEB, 2016). In addition, the definition of T10 is more suitable for the definition of a surjective function rather than one-to-one function definition. However, both teachers did not specify that A and B sets should be different sets from empty sets when defining.

\subsubsection{Defining Injective Function}

In this section, the pre-service teachers were asked to make a definition of injective function.

Table 2. Defining injective function

\begin{tabular}{lcc}
\hline & $\mathrm{f}$ & $\%$ \\
\hline Correct & 14 & 22.6 \\
Wrong & 29 & 46.8 \\
Null & 19 & 30.6 \\
\hline
\end{tabular}

According to Table 2, the vast majority of pre-service teachers wrote the definition of the function either wrong or with no description at all. Examples from the correct definitions:

T5=It can be defined as elements in A set maps some of the elements in B set as there is no empty element in $A$. That is, there should be empty elements in $B$ set.

$T 4=$ Given $A$ and $B$ sets different from empty set, in a mapping from $A$ to $B$, each element of $A$ maps an element in $B$ and there should be uncovered element in $B$, that is, it should not be surjective function.

Examples from wrong definitions:

$T 2=$ From $A$ and $B$ sets, randomly mapping f function on condition that each element in $A$ maps at least one element in $B$.

$T 40=$ For $A$ and $B$ sets, $f$ function from $A$ to $B$ in which each element of $A$ maps the same or different element in $B$.

When the incorrect definitions are examined, $\mathrm{T} 2$ and $\mathrm{T} 40$ do not explicitly state the conditions to be a function in functioning from A set to B set and the necessity for the elements to remain uncovered codomain.

3.1.3 Defining Constant Function

In this section, the pre-service teachers were asked to make a definition of constant function.

Table 3. Defining constant function

\begin{tabular}{lcc}
\hline & $\mathrm{f}$ & $\%$ \\
\hline Correct & 35 & 56.4 \\
Wrong & 20 & 32.3 \\
Null & 7 & 11.3 \\
\hline
\end{tabular}


According to Table 3, more than half of the pre-service teachers successfully defined constant function. Examples from the written correct definitions:

\section{$T 40=A$ and $B$ are two sets different from empty set, it is a relation that each element of $A$ maps only one} element of $B$.

$T 27=$ Given $A$ and $B$ sets different from empty set, if each element of $A$ maps only one element in $B$, this function we define from $A$ to $B$ is constant function.

Examples from the written wrong definitions:

$T 1=$ Each element of $A$ mapped only one element of $B$.

T50 $=$ It is that each element of $A$ maps one element of $B$.

When the wrong definitions are examined, T1 and T50 do not clearly specify the conditions required for a mapping to be performed from A to B before definition of constant function. If the function which "maps all elements of the definition set with one element of value set (MEB, 2016)" is constant function, T50 ignored the condition "mapping only with one element".

3.1.4 Defining Surjective Function

In this section, the pre-service teachers were asked to make a definition of surjective function.

Table 4. Defining surjective function

\begin{tabular}{lcc}
\hline & $\mathrm{f}$ & $\%$ \\
\hline Correct & 25 & 40.3 \\
Wrong & 18 & 29.1 \\
Null & 19 & 30.6 \\
\hline
\end{tabular}

According to Table 4, more than half of the pre-service teachers wrote the definition of the surjective function either wrong or with no description at all.

Examples from the correct definitions:

$T 27=$ Given $A$ and $B$ sets different from empty set, if each element of $A$ maps an element in $B$ and there is no element left, this relation is called surjective function.

T6=That each element of A maps an element in $B$ as there left no element is called surjective function.

Examples from the written wrong definitions:

T5=The elements in A maps the elements in $B$ and there left no element empty in $A$.

$T 15=I t$ is called as all the elements in the definition set maps one or more than one element in value set.

On analyzing the wrong definitions, considering the definition that "the function is that each element in the value set maps at least one element in definition set" (MEB, 2016), T15 stated that each element in the value set should be mapped but ignored that there should not be left any element empty in the definition set. While defining, T5, on the other hand, whether confused the concepts with each other as he could not grasp definition set and value set or did not understand surjective function completely so he defined it wrong.

\subsubsection{Defining Unit Function}

In this section, the pre-service teachers were asked to make a definition of unit function.

Table 5. Defining unit function

\begin{tabular}{lcc}
\hline & $\mathrm{f}$ & $\%$ \\
\hline Correct & 17 & 27.4 \\
Wrong & 33 & 53.2 \\
Null & 12 & 19.4 \\
\hline
\end{tabular}


According to Table 5, more than half of the pre-service teachers wrote the definition of the unit function either wrong or with no description at all.

Examples from the correct definition:

T34=When we processed each element in definition set under f function, they mapped themselves in the value set.

T17=Take $A$ and $B$ as two different sets. The images of the elements in $A$ under fmaps themselves again in $A$.

Examples from the wrong definitions:

$T 2=I t$ is the frelation that each element in $A$ maps its equivalent in $B$ in $A$ and $B$ sets.

$T 6=$ Every relation which is relation from $A$ to $A$ in which each element of $A$ is mapped again with $A$ set is called symmetric function.

On analyzing the wrong definitions, it can be said that it was ignored that the unit functions are "the function which maps each value in the definition set with itself" (MEB, 2016).

The definition of $\mathrm{T} 6$ can only be true that each element of A must map to itself, and that the matched sets must not be A set, but can be "B set or C set..." not that "every element of A is mapped to set A".

\subsection{Giving Appropriate Example to the Definition of Function}

The definition of function in AFWDLF was presented to the subjects as "Take A and B as two sets. The f rule that each element of A maps one and only one element in B is called as a function from A to B". When the daily life examples written by the subjects are examined, the results are written in Table 6 .

Table 6. Giving real life examples appropriate to the definition of function

\begin{tabular}{lcc}
\hline & $\mathrm{f}$ & $\%$ \\
\hline Correct & 137 & 44.1 \\
Wrong & 113 & 36.5 \\
Null & 60 & 19.4 \\
Total & 310 & 100 \\
\hline
\end{tabular}

When Table 6 is examined, it is seen that the correct examples of preservice teachers are more than the wrong examples.

Some of the correct examples are as follow;

$T 27=$ Set $A$ is the students attending TEOG test and set B is high schools set. And each student attending the test gain the right to register in one high school. As each student attending in the test will register one high school and no students will be left unregistered, a surjective function from A to $B$ can be defined.

$T 22=$ Set $A$ is the students in a class.

And set $B$ is what grade these students are (constant function).

$T 19=$ Set $A$ is the members in a family and set $B$ is their blood types.

There can be people in the same blood type in the family, or their blood type can be different. In addition, there can be no family member who has any blood type.

Examples from the wrong definition are as follow:

T39=Set $A$ is the children playing outside,

Set $B$ is the games being played. It is a mapping function from $A$ to $B$.

T19=Set $A$ is even numbers,

Set $B$ is square of even numbers, so the function defined from $A$ to $B$ is one-to-one and surjective function. 
$T 7=$ Set $A$ indicates any four people, set B is the fingerprints of these people. Everyone has only one fingerprint (unit function example).

When the wrong answers are analyzed, it can be said that some parts of the function definition are ignored. For example, in the example of T39, when one of the children playing outside is thought to be able to play more than one game, it is the case that an element in the definition set is matched to more than one element in the value set. The same situation can be seen in the example of T19. Since the square of positive even numbers and negative even numbers is equal to each other for the same numbers, for example, $-2,+2 \ldots$, there is a case of matching one element in the definition set with more than one element in value set. In the two examples given, examples are not appropriate to function definition, because it is not known completely how the elements of the set and the mappings should be exactly. In the example given by $\mathrm{T} 7$ about unit function, it was ignored that unit function is "the function which matches each element in definition set with itself" (MEB, 2016).

\subsubsection{Writing Real Life Examples for One-to-One Function}

In this section, pre-service teachers were asked to write a daily life example appropriate to one-to-one function.

In Table 7, the true-wrong frequency of daily life examples written by pre-service teachers about one-to-one function is indicated.

Table 7. Writing appropriate examples for one-to-one function in daily life examples

\begin{tabular}{lcc}
\hline & $\mathrm{f}$ & $\%$ \\
\hline Correct & 42 & 67.7 \\
Wrong & 13 & 21.0 \\
Null & 7 & 11.3 \\
\hline
\end{tabular}

When Table 7 is examined, it can be said that most of the pre-service teachers can successfully wrote examples about one-to-one function. Some of the correct answers are as follow;

$T 2=I t$ is a relation which tells us that the students in a classroom will obviously take their own bags from a room where their bags sit.

T31=It is that the plate numbers of our country match with the cities of our country.

$T 40=$ The uniform of the players in the national team. That is, let set $A$ be the national team players, and set $B$ be the uniforms that the players will wear. That each player wears his own uniform is one-to-one function.

Some of the wrong examples are as follow:

T13=There are clothes in four different colors in a store. You can buy at least one of them.

T6=Each child has one mother ( child can have a stepmother).

T15=The places where people from different professions work, liketeacher $\rightarrow$ school,doctor $\rightarrow$ hospital, engineer $\rightarrow$ factory.

Among the wrong answers, the store example is an example of another topic of mathematics in a similar way to one of the examples in function definition. The child-mother sample is a correct example as it is a function, but it is not one-to-one as the children are not defined well. The fact that two children are siblings will break one-to-one function rule. Similarly, the definition in the example about the professions is also wrong. People in the same occupation can work in different places as well as people in different professions can work in the same place.

3.2.2 Writing Daily Life Examples about Injective Function

In this section, pre-service teachers were asked to write a daily life example appropriate to injective function.

In Table 8, the true-wrong frequency of daily life examples written by pre-service teachers about injective function is indicated. 
Table 8. Writing appropriate examples for injective function in daily life examples

\begin{tabular}{lcc}
\hline & $\mathrm{f}$ & $\%$ \\
\hline Correct & 16 & 25.9 \\
Wrong & 25 & 40.3 \\
Null & 21 & 33.8 \\
\hline
\end{tabular}

According to Table 8, more than half of the pre-service teachers' daily life examples about injective function is either wrong or there is no example at all. Examples of the correct examples are as follow:

$T 18=4$ friends who left the house will go to a study center. 3 of them will be instructed in the same classroom. And 1 will attend another classroom. Both of 2 classrooms are left uncovered.

T24=Let set $A$ be children and set B be mothers. Each child has one mother. But each mother can have more than one child. And there also can be mothers who do not have children.

$T 41=3$ of 4 friends play football, one reads book. No one plays volleyball or handball.

Examples from the wrong answers:

T19=That the children of a family who goes to a hotel for holiday stay in the same room.

$T 22=A$ three has many branches.

T34=The favorite lesson of 3 people is Mathematics, and favorite lesson of 1 is Physics.

On analyzing the wrong answers, while the tree example does not carry function characteristics, the students in other examples wrote an example carrying function characteristics but the examples they wrote does not carry surjective function characteristics. It can be said that this is due to the fact that the information about the uncovered elements in the value set is not mentioned in the examples.

3.2.3 Writing Daily Life Examples about Constant Function

In this section, pre-service teachers were asked to write a daily life example appropriate to constant function.

Table 9 indicates the true-wrong frequency of daily life examples written by pre-service teachers about constant function.

Table 9. Writing appropriate examples for constant function in daily life examples

\begin{tabular}{lcc}
\hline & $\mathrm{f}$ & $\%$ \\
\hline Correct & 35 & 56.4 \\
Wrong & 23 & 37.2 \\
Null & 4 & 6.4 \\
\hline
\end{tabular}

When Table 9 is examined, it can be said that most of the pre-service teachers can successfully wrote examples about constant function.

Some of the correct answers are as follow:

$T 3=$ While set $A$ is the students in any classroom of our school, set $B$ is the branch of the classroom the students in, it is that the branch of the students in classroom is the same.

T61=The blood type of a person has been determined once in four years for four times, and these measurements are indicated with set $A$. Let set $B$ be all the blood types. As the blood type of the person will not change in years, the function from $A$ to $B$ is constant function.

T60 $=$ Set $A$ is the students in a classroom in a school and set $B$ is the teachers in the school. The form teacher of the students in this class is the same teacher. Therefore, the function defined from $A$ to $B$ is constant function.

Examples among the wrong examples: 
$T 57=$ Set $A$ is the students living in different cities and got into the university, and let set $B$ be any city. It is that the students in set a go to a city to study in university.

T49=Let set $A$ be four siblings. Let set $b$ be the mother of these siblings. The relation defined as these four siblings have one mother is constant function.

$T 43=$ Set $A$ is the families who go on holiday, and set B is the hotels for the holiday. As all of the families will go to the most benefitting hotel, the relation to be done is constant function.

The mistakes made about the constant function are caused by the lack of expression and the mistakes of the pre-service teachers who have made mistakes are substantially similar to each other. The given examples would be appropriate to constant function if T57 wrote it as "set A is living in different cities, getting into the same university", and if T49 wrote it "biological mother" or "each sibling has one mother", explaining "mother" concept in detail as one or more of the siblings could have a second mother. In the example of T43, as each family would have different budget, the most benefitting hotel would be different for each family. That is, it wouldn't be the same hotel. Therefore, there is a lack of expression in this example.

\subsubsection{Writing Daily Life Examples about Surjective Function}

In this section, pre-service teachers were asked to write a daily life example appropriate to surjective function.

Table 10 indicates the true-wrong frequency of daily life examples written by pre-service teachers about surjective function.

Table 10. Writing appropriate examples for surjective function in daily life examples

\begin{tabular}{lcc}
\hline & $\mathrm{f}$ & $\%$ \\
\hline Correct & 32 & 51.6 \\
Wrong & 18 & 29.1 \\
Null & 12 & 19.3 \\
\hline
\end{tabular}

When Table 10 is examined, it can be said that most of the pre-service teachers can successfully write examples about surjective function.

Some of the correct answers are as follow:

T38=2 apples were given equally to 2 people. The remaining 1 person was given 2 apples as he liked apple very much. There were no one or no apple left uncovered.

$T 22=4$ people will check into 3 different hotels. 2 people will check into 2 different hotels, and the other two will check into the 1 hotel left.

$T 44=$ Let set $A$ indicates the students in a classroom and let set $B$ indicates the scores of the students from mathematics. The following mapping from $A$ to $B$ is surjective function: all the students got only one score and more than one student got the same score.

Examples from wrong examples:

$T 2=$ Let set $A$ be teachers and let set $B$ be students in any classroom. The teachers will punish the students in set $B$. A student gets punished by two different teachers.

T16=Let set $A$ indicate students and set B indicate sports branches. It is the mapping that each student chooses one of the sports branches.

T36=4 people will stay in a hotel. 2 of them will stay in one hotel, and other two of them will stay in different hotels.

On analyzing the wrong answers, it is thought that the pre-service teachers did not write any information about the empty element in value set related to the surjective function or ignored this or ignored what conditions a function should have. In T2's example, as the situation "there would be a teacher who wouldn't punish" will left elements empty in value set, it does not fulfill the condition to be a function. As T16's example would be appropriate to one-to-one function, it can be interpreted that T16 does not know the definition of surjective function. It can be said that the fact that T16 did not write the asked definition of surjective function concept verifies this. In T36's "hotel example", as no information about the fact that there would be another hotel in that 
city was written. If there were another hotel in the city, the relation wouldn't be surjective as there would be another hotel in the city.

\subsubsection{Writing Daily Life Examples about Unit Function}

In this section, the pre-service teachers were asked to write daily life examples related to unit function.

Table 11. Writing daily life examples about unit function

\begin{tabular}{lcc}
\hline & $\mathrm{f}$ & $\%$ \\
\hline Correct & 12 & 19.4 \\
Wrong & 34 & 54.8 \\
Null & 16 & 25.8 \\
\hline
\end{tabular}

On analyzing Table 11, it can be said that the pre-service teachers were not quite successive in writing daily life examples related to unit function.

Examples from the correct examples:

$T 17=$ Let $F$ be an elevator and $A$ be the people getting into it. And let B the ones leaving the elevator. When someone from A gets into the elevator, s/he leaves the elevator as who s/he is in the beginning. This applies to everyone.

T32=Let set $A$ those who look in the mirror and set B be their images on the mirror. Anyone who looks in the mirror will see himself.

Examples from the wrong examples:

T16 $=4$ candies will be distributed to 4 children. Each child is given one candy and the distribution is completed.

T27=Each mother has one child and each child has one mother .

T22=From two different groups consisting of twins, matching the twins in group A with his own twin in group $B$.

On analyzing the wrong answers, it was determined that some of the pre-service teachers confuse unit function with one-to-one function and so they wrote examples about one-to-one function instead of unit function.

Evaluating the obtained data as a whole, it was determined that the pre-service teachers are more successful in defining one-to-one and constant function and relating them with daily life while they are less successful about unit function. It was concluded from some of the examples written by the pre-service teachers that they confuse functions with different subjects of mathematics. In spite of their ability to know the type of the function and the correct description of the function, some pre-service teachers could not write examples for this type when they were giving examples. On analyzing the wrong answers as a whole, it has been determined that in a significant majority of the answers, the answers of pre-service teachers are in accordance with the function definition but do not carry the characteristics of the related function. Despite the fact that no instruction was given to the pre-service teachers that their examples should be related to situation about daily life, the vast majority of them preferred to tell examples through mother-child, the image on the mirror, the student-class branch, the student-form teacher.

\section{Results and Discussion}

In the light of the research findings, it was found that the pre-service teachers had a deficiency in understanding the function definition and basic function concepts. With this result, the existence of the research problem was reaffirmed. According to the results of the research, it was seen that the pre-service teachers were not able to write the definition of function types successfully (one-to-one function $66.2 \%$, injective function $22.6 \%$, constant function $56.4 \%$, surjective function $40.3 \%$, unit function $27.4 \%$ ), however, it was seen that their success rate is relatively higher in certain function types. This result shows that the vast majority internalized the definition of only a few of the functional types. According to research findings, it can be said that the deficiencies in the definition of function originate from the fact that the concepts of the definition set and the value set are not fully understood. This result can be thought of as a sign of the existence of deficiencies in the skills of pre-service 
teachers in sub problem 1, such as analogy, communication and association, which are very important for mathematics.

Vinner and Dreyfus (1989) and Işık, Albayrak and İpek (2005) have studied the perceptions of pre-service teachers about the functions and their misconceptions regarding the functions. The result of the study is parallel with the results of Winner and Dreyfus (1989); Ișık Albayrak and İpek (2005); Şanlı Şandır (2006). The fact that the results of the research are related to each other can be interpreted as the fact that the first subproblem of the research is accurate and it increases the reliability of the research. In this respect, it is believed that this research has been complementary to previous researches.

According to the results of the research, the realization level of sub-problem 2 "adapting the information and skills they have acquired about the function types to their daily lives" is $66.7 \%$ for one-to-one function, $25.9 \%$ for injective function, $56.4 \%$ for constant function, $51.6 \%$ for surjective function and 19.4 for unit function, and this rate is quite low. However, it has been determined that pre-service teachers wrote the wrong examples about one-to-one function, surjective function, and other types of functions and it is assumed that the situation which causes these wrong examples is caused by pre-service teachers' inability to interpret the definition of the function. That is, a deficiency in the definition of function types leads to wrong example about the function.

Bayazit and Aksoy (2013) determined that associating these concepts with everyday life in the teaching of basic concepts of function will contribute to the formation of permanent learning in students. However, the fact that one of the purposes of mathematics teaching was determined in TTKB (2016) to train individuals who can integrate mathematical applications with daily life can be interpreted that conducting this research was a necessity. In addition, we believe that the results of the study conducted by Türkeli Şandır (2006) analyzing the ability of the pre-service teachers to give daily life examples related to some concepts of functions are parallel with the results of our study, which is a confirmation for the reliability of our study. The different aspect of our study from other researches is that it also includes writing examples about types in terms of descriptive statistics in addition to the fact that it includes similar results in terms of function types.

In the research, when the examples written by the pre-service teachers about the concept of function were examined holistically, the majority of the pre-service teachers wrote examples through "mother-child, teacher-student, image on the mirror". Ural (2006) stated in his study that analogies can be used in the teaching of the concept of function with reference to established between "mother-child". In this study, it can be considered that the reason why pre-service teachers focused on one type of example may be due to the fact that the pre-service teachers learned the subject through analogy "mother-child". However, knowing some expressions such as "action of converting the input to output, supply and demand, quality used material, ..." of the function may increase the example variation. It can also be considered that the very few use of everyday tasks (taking a bus, students' gathering in the class, that each student sits on a chair, etc.) and everyday objects (everybody has an identity card, each country has a flag, etc.) in giving examples indicate that the students have difficulty in associating concept with the daily life.

\section{Recommendations}

In the light of the findings and results of the study, the following recommendations are given:

-In addition to teaching function concept by associating it with daily life can contribute to permanent learning, it will make learning more attractive as it will allow the students to know how and where to use the acquired information.

-With the change to be done in teaching of function concept, understanding other concepts related to function concept and used in mathematics will be easier and so the number of people who understand mathematics will increase and teaching mathematics can be a lot easier.

-Deficiencies about this can be eliminated by supplementing the contents of undergraduate programs and Secondary School textbooks with associating the concepts and definitions with daily life.

\section{References}

Altun, M. (1998). Matematik Öğretimi. Açıöğretim Fakültesi Yayınları, 591.

Ay, S. (2008). Lise seviyesinde öğrencilerin günlük yaşam olaylarını açıklama düzeyi ve buna kimya bilgilerinin etkisi. Yayınlanmamış yüksek lisans tezi, Marmara Üniversitesi, İstanbul.

Bayazit, İ., \& Aksoy, Y. (2013). Fonksiyon kavramı: Epistemolojisi, algı türleri ve zihinsel gelişimi. Erciyes Üniversitesi Fen Bilimleri Enstitüsü Dergisi, 29(1), 1-9. 
Bourbaki, N. (2004). Elements of Mathematics Functions of a Real Variable: Elementary Theory. Berlin: Springer. https://doi.org/10.1007/978-3-642-59315-4

Burke, K. A., Greenbowe, T. J., \& Hand, B. M. (2006). Implementing the science writing heuristic in the chemistry laboratory. Journal of Chemical Education, 83(7), 1032-1038. https://doi.org/10.1021/ed083p1032

Coştu, B., Ayas, A., \& Niaz, M. (2010). Promoting conceptual change in first years tudents' understanding of evaporation. Chemistry Education Research and Practice, 11(1), 5-16. https://doi.org/10.1039/C001041N

Creswell, J. W. (2012). Qualitative inquiry and research design: Choosing among five approaches. Sage publications.

Dönmez, A. (2002). Matematiǧin öyküsü ve serüveni: Dünya matematik tarihi ansiklopedisi. Toplumsal Dönüşüm.

Duran, M., Doruk, M., \& Kaplan, A. (2017). Argümantasyon tabanlı olasılık öğretiminin ortaokul öğrencilerinin başarılarına ve kaygılarına etkililiğinin incelenme. Eğitimde Kuram ve Uygulama, 13(1), 55-87.

Eisenberg, T. (2002). Functions and associated learning difficulties. In Advanced mathematical thinking (pp. 140-152). Springer Netherlands. https://doi.org/10.1007/0-306-47203-1_9

Enginar, İ., Saka, A., \& Sesli, E. (2002). Lise 2 ögrencilerinin biyoloji derslerinde kazandıkları bilgileri güncel olaylarla ilişkilendirebilme düzeyleri (ss 21). V. Ulusal Fen Bilimler ve Matematik Eğitimi Kongresi, ODTÜ, Ankara.

Hitt, F. (1998). Difficulties in the Articulation of Different Repsentations Linked to the Concept of Function. Journal of Mathematical Behavior, 17(1), 123-134. https://doi.org/10.1016/S0732-3123(99)80064-9

Işık, C., Albayrak, M., \& İpek, A. S. (2005). Matematik öğretiminde kendini gerçekleştirme. Kastamonu Eğitim Dergisi, 13(1), 129-138.

Kanalmaz, T. (2010). İlköğretim 8. sinıf matematik dersi ölçme ögrrenme alanında analoji yöntemine dayalı ögretimin ögrencilerin akademik başarılarına etkisi (Unpublished master's thesis). Gazi Üniversitesi, Ankara.

Kleiner, I. (1989). Evolution of thefunctionconcept: A briefsurvey. The College Mathematics Journal, 20(4), 282-300. https://doi.org/10.2307/2686848

Koçak, C., \& Önen, A. S. (2012). Kimya Konularının Günlük Yaşam Konsepti Çerçevesinde Değerlendirilmesi. Hacettepe Üniversitesi Eğitim Fakültesi Dergisi, 42(42).

Küçükturan, G. (2003). Okul öncesi fen öğretiminde bir teknik: Analoji. Milli Ĕgitim Dergisi, 157, 16-21.

Markovits, R., Eylon, B. S., \& Brukheimer, M. (1986). Functions Today and Yesterday. For the Learning of Mathematics, 6(2), 18-28.

National Council of Teachers of Mathematics. (2000). Principles and standards for school mathematics. Reston, VA20191-9988, NCTM.

Ponte, J. P. D. (1992). The history of the concept of function and some educational implications. The Mathematics Educator, 3-8.

Sajka, M. (2003). A secondary school student's understanding of the concept of function-A case study. Educational Studies in Mathematics, 53(3), 229-254. https://doi.org/10.1023/A:1026033415747

Shulman, L. (1986). Those Who Understand: Knowledge Growth in Teaching. Educational Researcher, 15, 4-14. https://doi.org/10.3102/0013189X015002004

Spellman, B. A., \& Holyoak, K. J. (1996). Pragmatics in Analogical Mapping. Cognitive Psychology, 31, 307-346. https://doi.org/10.1006/cogp.1996.0019

Sternberg, R. J. (1999). A Triarchic Approach to the Understanding and Assessment of Intelligence in

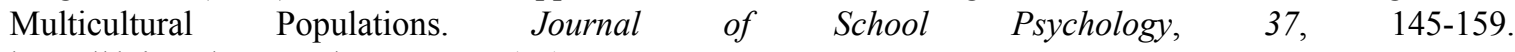
https://doi.org/10.1016/S0022-4405(98)00029-6

Torun, F., \& Şahin, S. (2016). Argümantasyon temelli sosyal bilgiler dersinde öğrencilerin argüman düzeylerinin belirlenmesi. Eğitim ve Bilim, 41(186), 233-251.

TTKB. (2016). Retrieved from http://ttkb.meb.gov.tr/www/ogretim-programlari/icerik/72 
Türkeli Şandır, Y. (2006). Fonksiyon kavramı hakkında ögrretmen adaylarının görüşleri üzerine bir fenomenografik çalışma (Unpublished master's thesis). Gazi Üniversitesi Eğitim Bilimleri Enstitüsü, Ankara.

Umay, A., \& Kaf, Y. (2005). Matematikte kusurlu akıl yürütme üzerine bir çalışma. Hacettepe Üniversitesi Eğitim Fakültesi Dergisi, 28, 188-195.

Ural, A. (2006). Fonksiyon öğreniminde kavramsal zorluklar. Ege Eğitim Dergisi, 7(2).

Vinner, S., \& Dreyfus, T. (1989). Images and definitions for the concept of function. Journal for Research in Mathematics Education, 356-366. https://doi.org/10.2307/749441

\section{Copyrights}

Copyright for this article is retained by the author(s), with first publication rights granted to the journal.

This is an open-access article distributed under the terms and conditions of the Creative Commons Attribution license (http://creativecommons.org/licenses/by/4.0/). 